UTILITY: Jurnal IImiah Pendidikan dan Ekonomi

Volume 3, No. 2, Agustus 2019: Page 75-84

ISSN 2549-1377 (Print) || ISSN 2549-1385 (Online)

Available online at http://journal.stkipnurulhuda.ac.id/index.php/utility

\title{
PENERAPAN DOUBLE ENTRY BOOKKEEPING BASIS FOKUS PENERAPAN PADA LIABILITIES SEBAGAI KOMITMEN MORAL, TANGGUNG JAWAB DAN KINERJA LEMBAGA SOCIAL, PUBLIK DAN INSTITUSI PEMERINTAHAN
}

\author{
Husni Mubarak ${ }^{1}$ \\ Jurusan Administrasi Niaga Program Studi Akuntansi Sektor Publik \\ Politeknik Negeri Bengkalis \\ Jl. Bathin Alam Sungai Alam-Bengkalis-Riau \\ Email: husnimubarak@polbeng.ac.id
}

\begin{abstract}
Artikel ini fokus pada pembukuan entri ganda (DEB). Fokus penilaian dari artikel ini adalah pada pengembangan penggunaan persamaan akuntansi Aset $=$ Kewajiban + Ekuitas $(\mathrm{A}=\mathrm{L}+\mathrm{E})$. Mereka yang biasa digunakan untuk pendekatan untuk memahami akuntansi dan pengembangan. Konsep ini adalah perubahan dalam persamaan $A=L+E$ menjadi A-E $=\mathrm{L}$ untuk transformasi dari kompleksitas transaksi. Persamaan akuntansi ini (A-E $=\mathrm{L}$ atau $\mathrm{L}=\mathrm{A}$ E) hanya hanya konsep untuk pemahaman kompleks dan totalitas menggunakan bagian dari konsep akuntansi. Artikel ini menjelaskan DEB dalam penggunaan untuk keuangan publik, pemerintah, dan lembaga sosial. Arah transformasi penyederhanaan konsep ini adalah untuk memahami kompleks dan totalitas persamaan dan penggunaan akuntansi dari kewajiban.
\end{abstract}

Keywords : DEB, equiation, liabilities, concept, Accounting.

\section{PENDAHULUAN}

Tren yang berkembang saat ini, beberapa lembaga keuangan non bisnis baik lembaga social, publik dan pemerintah selalu melampirkan kinerja keuangan yang baik dan akuntabel. Baiknya kinerja dan laporan menandakan bahwa baiknya sistem ketata kelolaan sebuah organisasi / lembaga serta tingginya tingkat pertanggungjawaban dan komitmen dari sebuah organisasi.

Meskipun tidak semua lembaga social dan publik serta pemerintahan teredukasi dengan baik terhadap sebuah kemitmen pemahaman dan tanggungjawab secara universal, kenyataannya bahwa laporan keuangan mampu dikelola dengan baik, penuh hati hati dan terjaga akan akuntabilitasnya serta dapat di percaya/ terandalkan.

Tidak semuanya lembaga di atas berkinerja baik. Tidak jarang kita temukan dibeberapa daerah yang lembaga social dan publik memiliki masalah dengan standar pelaporan, alur transaksi dengan terlapor secara baik, benar, dan berbagai permasalah lainnya juga tidak jarang kita temukan bahwa lembaga tersebut memiliki beban utang yang jumlah cukup signifikan.

Terkadang utang tersebut merupakan komitmen jangka panjang, tidak hanya berpotensi membebankan satu waktu tertentu saja, juga melibatkan beberapa priode kepengurusan. Kewajiban (liabilities) merepresentasikan sebagian sumber dana dari 


\section{Husni Mubarak $^{1}$}

asset badan usaha berupa potensi jasa (manfaat) fisis dan non fisis yang merupakan penyediaan barang dan jasa (Suwardjono 2006).

Pada system Lembaga pemerintahan, meskipun pelaporan keuangan tertata dengan baik, kompleks dan terandalkan, beban utang dan kewajiban utang tetap muncul. Tidak hanya di sektor pemerintahan, di Negara kita, hampir sebagian besar lembaga keuangan milik Negara melalui BUMN memiliki utang investasi yang cukup signifkan.

Komitmen munculnya utang merupakan kebijakan, strategi dan keputusan masa lalu dan saat ini yang berimbas di masa depan. SAFC menitik beratkan bahwa kewajiban merupakan pengorbanan sumber ekonomi masa depan yang timbul saat ini sebagai sebuah keharusan. Keharusan ini merupakan kebijakan dan buah hasil dari keputusan saat ini yang timbul dan berdampak masa depan.

Keterlibatan komitmen utang ini tidak hanya melibatkan proses dan masa jabatan/pimpinan/masa kerja tertentu saja atau priode tertentu, juga melibatkan pihak terkait yang berkomitmen sebagai penerus kebijakan dan pemanfaatan dimaksud dalam jangka waktu yang cukup lama.

Untuk permasalahan ini, sistem dan pengembangan akuntansi seharusnya memiliki komitmen dan menfasilitasi entitas laporan yang berbasis kewajiban/utang sebagai komponen utama dalam unsur pelaporan. Pemanfaatan yang lebih luas diharapakan bahwa publik memiliki informasi yang pasti untuk mengukur, menilai serta membenarkan informasi tersebut sebagai hasil dari sistem tersebut.

\section{PERSAMAAN AKUNTANSI ASSET, LIABILITIES DAN EQUITY}

Persamaan akuntansi sederhana yang di uangkapkan oleh Para ahli akuntansi dalam mendesain konsep ini dapat kita temukan di beberapa referensi buku introduction accounting sebagai suatu kebutuhan yang menfasilitasi pemahaman lebih luas dan komperhensif. Mubarak (2018) menjelaskan bahwa Beberapa ahli yang dimaksud diantaranya Gillespie, et al. (2004), Albrecht, et al. (2008), Weygandt, et al. (2009, 2010), Phillips, et al. (2011), Weetman (2011), Needles \& Power (2007), Horngren, et al. (2012), Stickney, et al., 2010, Alexander \& Nobes 2007, 2010, libby \& short 2009, warren, et al., 2012, albactic \& Stice 2011, Britton \& Waterston 2006 merupakan para ahli yang menulis buku tentang Financial Accounting, dan beberapa ahli seperti Weygandt et al., 2012, Needles et al., 2011, Ireland 2005, merupakan para ahli yang menulis buku tentang Principle Accounting or Accounting Principle. Pada prinsipnya kedua jenis buku tersebut mengembangkan dan menjelaskan konsep yang sama dari accounting equity untuk DEB in Accounting concept.

Penelusuran untuk komponen pembentukan persamaan akuntansi oleh Luca Pacioli (Asset=Liabilities+Equity) juga diadopsi oleh beberapa penulis dan dimodifikasi pengembangannya. Selanjutnya persamaan tersebut di antaranya berupa persamaan Asset=Liabilities +Owners Equity oleh Warren, et.al, (2012), Albrecht, et.al, (2008), Weygandt, et.al, (2012), Warren, et.al, (2012) Alexander \& 


\section{PENERAPAN DOUBLE ENTRY BOOKKEEPING BASIS FOKUS PENERAPAN PADA LIABILITIES SEBAGAI KOMITMEN MORAL, TANGGUNG JAWAB DAN KINERJA LEMBAGA SOCIAL, PUBLIK DAN INSTITUSI PEMERINTAHAN}

nobes, (2007). Penjabaran yang sama seperti Stickney, et.al, (2010), Needles, et.al, (2008), Libby, et.al, (2009), Needles \& Powers (2007) berupa persamaan Asset=Liabilities+ Stockholders Equity.

Selain itu persamaan Asset=Liabilities+Equity oleh Gillespie, et.al, (2004), maupun persamaan Asset=Ownership Interest+Liabilities Oleh Weetman (2011). Intinya, keseluruhan persamaan diatas merupakan persamaan yang di adobsi dari konsep sebelumnya $A=L+E$. Konsep yang di kembangkan baik oleh Weygendt et al., (2010) atau Needles \& Powers (2007) membuat dan mengembangkan persamaan akuntansi sebagai sebuah entitas kesatuan bisnis/usaha. Adapun konsep tersebut; Asset $=$ liabilities + Common Stock + Retained Earning - Devident + Revenues Expense $(\mathrm{A}=\mathrm{L}+\mathrm{CS} / \mathrm{E}+\mathrm{RE}-\mathrm{D}+\mathrm{R}-\mathrm{Ex})$.

Penyederhanaan persamaan akuntansi dari semua para ahli diatas mampu di simpulkan dengan persamaan yang komplek yaitu berupa Asset + Devident + Expense $=$ Liabilities + Common Stock + Retained Earning + Revenues $(A+D+E x=L+C S+R E+R)$.

\begin{tabular}{ccc}
\hline$A$ & $=$ & $L+E$ \\
\hline$A$ & $=$ & $L+C S / E+R E-D+R-E x$ \\
\hline$A+D+E x$ & $=$ & $L+C S / E+R E+R$
\end{tabular}

Stickney et al., (2010) mengembangkan kompleksitas transaksi untuk persamaan akuntansi hampir sama dengan Weygendt dan yang lainnya, yakni Asset $=$ Liabilities + Shareholders' Equity $(\mathrm{A}=\mathrm{L}+\mathrm{SE})$. Selanjutnya Shareholders' Equity merupakan kompenen Contributed Capital + Retained Earnings, sehingga penjabaran rusum ini dimodifikasi menjadi Asset $=$ Liabilities + Contributed Capital + Retained Earnings $(\mathrm{A}=\mathrm{L}+\mathrm{CC}+\mathrm{RE})$.

Retained Earnings merupakan komponen unsur penjabaran Retained Earnings Beginning of Period + Net Income for Period - Dividends for Period. Selanjunya Stickney et al., (2010) mengembangankan formula persaman ini menjadi kompleksitas transaksi menjadi Asset $=$ Liabilities + Contributed Capital + Retained Earnings Beginning of Period + Net Income for Period - Dividends $(\mathrm{A}=\mathrm{L}+\mathrm{CC}+\mathrm{RE}+\mathrm{NI}-$ D).

Dalam pelaporan Net Income for Period merupakan kombinasi untuk komponen dari Revenues for Period - Expenses for Period. Penjabaran dari rangka konsep ini membentuk konstruk untuk kombinasi rumus akuntansi disempurnakan menjadi Asset $=$ Liabilities + Contributed Capital + Retained Earnings Beginning of Period + Revenue - Expense - Dividends $(\mathrm{A}=\mathrm{L}+\mathrm{CC}+\mathrm{RE}+\mathrm{R}-\mathrm{Ex}-\mathrm{D})$.

\begin{tabular}{ccc}
\hline $\mathrm{A}$ & $=$ & $\mathrm{L}+\mathrm{SE}$ \\
\hline $\mathrm{A}$ & $=$ & $\mathrm{L}+\mathrm{CC}+\mathrm{RE}$ \\
\hline $\mathrm{A}$ & $=$ & $\mathrm{L}+\mathrm{CC}+\mathrm{RE}+\mathrm{RI}-\mathrm{D}$ \\
\hline $\mathrm{A}$ & $=$ & $\mathrm{L}+\mathrm{CC}+\mathrm{RE}+\mathrm{R}-\mathrm{Ex}-\mathrm{D}$
\end{tabular}

Weetmen (2011) dan Alexander \& Nobes (2010) memperkenalkan rumus akuntansi yang membuat persamaan berbeda dari Weygendt dan yang lainnya. 


\section{Husni Mubarak $^{1}$}

Konsep yang di kembangkan Weetmen ini merupakan suatu entitas bisnis untuk mengukur nilai kepemilikan murni. Adapun persamaannya antara lain (Weetmen 2011); Assets - Liabilities $=$ Ownership Interest $(\mathrm{A}-\mathrm{L}=\mathrm{OI} / \mathrm{E})$ atau persamaan itu bisa di simulasikan berbeda Assets = Ownership Interest + Liabilities $(A=O l / E+L)$ selanjutnya persamaan tersebut untuk kompleks transaksi; Assets - Liabilities = Ownership Interest +/- Capital Contribution or Withdrawn + Profit. (A-L=Ol+/$\mathrm{CC} / \mathrm{W}+\mathrm{P})$.

\begin{tabular}{ccc}
\hline $\mathrm{A}-\mathrm{L}$ & $=$ & $\mathrm{Ol} / \mathrm{E}$ \\
\hline $\mathrm{A}-\mathrm{L}$ & $=$ & $\mathrm{Ol} / \mathrm{E}+\mathrm{L}$ \\
\hline $\mathrm{L}-\mathrm{O}$ & $=$ & $\mathrm{Ol} / \mathrm{-CC} / \mathrm{W}+\mathrm{P}$
\end{tabular}

Perbedaan konsep juga dikembangkan untuk persamaan mencari Profit, untuk persamaan pada pelaporan rugi laba (income statement) dengan rumus Profit $=$ Revenue - Expense ( $\mathrm{P}=\mathrm{R}$-Ex). Rumus tersebut bisa di kembangkan Revenue Expense $=$ Profit $(\mathrm{R}-\mathrm{Ex}=\mathrm{P})$ untuk konsep yang sama (Weetmen 2011). Selanjutnya Weetmen menyempurnakan persamaan akuntansi dengan mengembangkan terobosan baru untuk laporan arus kas (Statement Cash Flow) dengan membuat persamaan Cash Flow = Cash inflows to the enterprise - Cash outflows from the enterprise $(\mathrm{CF}=\mathrm{Ci}-\mathrm{Co})$ atau persamaan itu sama dengan Cash inflows - Cash outflows $=$ change in cash asset $(\mathrm{Ci}-\mathrm{Co}=\mathrm{CF})$.

Pengembangkan konsep selanjutnya dikembangkan oleh Alexander \& Nobes (2010), menjelaskan persamaan akuntansi pada perspektif akuntansi yang sama dengan Weetmen. Persamaan tersebut mengemukakan konsep diantaranya Assets = Owner's Equity + Liabilities ( $\mathrm{A}=\mathrm{OE}-\mathrm{L})$ atau persamaan itu disederhanakan untuk Owner's Equity $=$ Assets - Liabilities $(\mathrm{OE}=\mathrm{A}-\mathrm{L})$. Selanjutnya persamaan itu di kembangkan menjadi Owner's equity $=$ Assets - Liabilities $=$ Net assets $(\mathrm{OE}=\mathrm{A}-\mathrm{L}=\mathrm{NA})$ atau sama artinya persamaan itu sama dengan penyederhanaan Owner's equity = Net assets $(\mathrm{OE}=\mathrm{NA})$.

Selanjutnya (Alexander \& Nobes, 2010) perubahan kepemilikan dari priode sebelumnya (1) menuju periode selanjutnya (2) di samakan dengan perubahan Owner's equity - Owner's equity sebelumnya = perubahan Profit - perubahan Drawings (OE2-OE1 = P2- D2). $\mathrm{p}$ persamaan tersebut bisa di samakan Owner's equity sebelumnya + perubahan Profit - perubahan Drawings = perubahan Owner's equity $(\mathrm{OE} 1+\mathrm{P} 2-\mathrm{D} 2$ = OE2). Untuk mencari laba sendiri Profit = Revenue Expense $\mathrm{P} 2=\mathrm{R} 2-\mathrm{Ex} 2$ maka untuk perubahan $\mathrm{A}-\mathrm{L}=\mathrm{OE}+\mathrm{R}-\mathrm{Ex}$ atau persamaan bisa dengan $A+E x=O E+R+L$.

\section{RASIONALITAS PERSAMAAN KOMPONEN LIABILITIES}

Dasar asumsi ilmiah adalah ketika sebuah unsur logika persamaan mampu dijelaskan pada konsep dan kaidah yang tepat dalam penggunaannya. Namun jika unsur itu hanya memenuhi kriteria persamaan, dan tidak mampu mengungkapkan untuk konsep keilmuan serta kaidah keilmiahannya, baru berdampak fatal.

Untuk pernyataan pengembangan kosntruk liabilities tidak banyak diungkapkan 


\section{PENERAPAN DOUBLE ENTRY BOOKKEEPING BASIS FOKUS PENERAPAN PADA LIABILITIES SEBAGAI KOMITMEN MORAL, TANGGUNG JAWAB DAN KINERJA LEMBAGA SOCIAL, PUBLIK DAN INSTITUSI PEMERINTAHAN}

pada penelitian dan pengembangan konsep akuntansi. Mubarak (2017) mengemukakan bahwa persamaan akuntansi untuk liabilities bisa diungkapkan dengan persamaan $A-E=L$. Pengungkapan ini menjelakan bahwa entitas akuntansi lebih mengutamakan kewajiban dalam pengungkapan akuntansi berentitas publik. Karena dasar keinginan yang lebih kuat adalah mengungkapkan kepada publik apa yang menjadi kewajiban dimasa depan atas komitmen saat ini.

Seperti pada konsep berikut ini bahwa untuk persamaan akuntansi teori pengembangan Pacioli bahwa persamaan akuntansi pertama Assets = Liabilities + Equity $(\mathrm{A}=\mathrm{L}+\mathrm{E})$ ini mampu di terima secara konsep dan keilmiahannya ketika diungkapkan menjadi persamaan kedua yang berbeda Assets - Liabilities = Equity (A$\mathrm{L}=\mathrm{E}$ ). Selanjutnya persamaan ketiga ini juga memenuhi unsur perubahan matematika Assets - Equity $=$ Liabilities $(\mathrm{A}-\mathrm{E}=\mathrm{L})$ adalah sangat memungkinkan. Dari sekian banyak pendapat para ahli, untuk persamaan yang ketiga ini tidak ada yang mengungkapkan tentang persamaan tersebut bisa diterima untuk logika dan alasannya. Pada bagian ini penulis hanya mengungkapkan analisis persamaan matematikanya.

Ketika Asset - Equity = Liabilities $(\mathrm{A}-\mathrm{E}=\mathrm{L})$, persamaan ini bisa dikembangkan dengan persamaan matematika sederhana dimana $A-E=L$ sama artinya dengan $L=A-$ E. Selanjutnya untuk penjabaran perluasan persamaan ketika menambah unsur pendapatan, maka persamaan ini menjadi; Asset - Contributed Capital - Net Income = Liabilities (A-CC-NI=L), dan ketika persamaan ini memiliki unsur pendapatan dan biaya maka; Asset - Contributed Capital - Net Income (Revenues + Expense) $=$ Liabilities (A-CC-NI(R-Ex)=L), dengan perluasan persamaan akan menjadi; Asset Contributed Capital - Retained Earning + Devident - Revenues + Expense $=$ Liabilities (A-CC/E-RE+D-R+Ex=L). Jika berdasarkan persamaan diatas, pengungkapan unsur pendapatan sudah lebih dahulu diketahui tanpa harus mengetahui komponen kewajiban terlebih dahulu.

Selanjutnya persamaan $\mathrm{A}-\mathrm{E}=\mathrm{L}$ yang orientasi utama focus pada liabilities, beberapa referensi menjabarkan konponen akun-akun konstruknya. Albrecht, et.al, (2008) liabilities merupakan komponen Acc. Payable + Note Payable + Other Payable (Ac.P+NP+ Ot.P). Sementara pendapat Needles, et.al, (2008) komponen akun liabilities memuatkan unsur current liabilities+ long term liabilities (Cr.L+LT.L). Pendapat lain seperti Weygandt, et.al, (2012), Warren, et.al, (2012) komponen liabilities adalah Acc.Payable. Dari pengungkapan di atas, konstruk pembentukan komponen liabilities dipaparkan pada tabel berikut.

\begin{tabular}{ccc}
\hline $\mathrm{A}$ & $=$ & $\mathrm{L}+\mathrm{E}$ \\
\hline $\mathrm{A}-\mathrm{E}$ & $=$ & $\mathrm{L}$ \\
\hline $\mathrm{A}-\mathrm{E}$ & $=$ & $\mathrm{L}(\mathrm{Cr} \cdot \mathrm{L}+\mathrm{LT} \cdot \mathrm{L})$ \\
\hline $\mathrm{A}-\mathrm{E}$ & $=$ & $\mathrm{Cr} . \mathrm{L}(\mathrm{Acc} . \mathrm{P}+\mathrm{NP})+\mathrm{LT} \cdot \mathrm{L}(\mathrm{Ob}+\mathrm{Bk}+++)$ \\
\hline
\end{tabular}




\section{Husni Mubarak $^{1}$}

Untuk kombinasi pelaporan Net Income for Period merupakan kombinasi untuk komponen dari Revenues for Period - Expenses for Period. Penjabaran dari rangka konsep ini untuk pembentukan perbedaan dari kombinasi rumus akuntansi yang telah disempurnakan menjadi Asset - Contributed Capital - Retained Earnings Beginning of Period - Revenue + Expense + Dividends $=$ Liabilities $(\mathrm{A}-\mathrm{CC}-\mathrm{RE}-\mathrm{R}+\mathrm{Ex}+\mathrm{D}=\mathrm{L})$. jika teori sebelumnya mengungkapkan bahwa $\mathrm{A}-\mathrm{L}=\mathrm{E}$ berarti sama Nett Asset $=$ Equity $(\mathrm{NA}=\mathrm{E})$, maka untuk persamaan ini Asset - Equity $=$ Liabilities $(\mathrm{A}-\mathrm{E}=\mathrm{L})$ atau persamaan Asset - Net Equity $=$ Liabilities $(\mathrm{A}-\mathrm{NE}=\mathrm{L})$ sama berarti Nett Asset $=$ Liabilities (NA=L).

\begin{tabular}{ccc}
\hline $\mathrm{A}-\mathrm{E}$ & $=$ & $\mathrm{L}$ \\
\hline $\mathrm{A}-\mathrm{CC} / \mathrm{E}+\mathrm{D}+\mathrm{Ex}$ & $=$ & $\mathrm{L}$ \\
\hline $\mathrm{A}-\mathrm{CC} / \mathrm{E}-\mathrm{RE}+\mathrm{D}-\mathrm{R}+\mathrm{Ex}$ & $=$ & $\mathrm{L}$ \\
\hline $\mathrm{A}-\mathrm{NE}$ & $=$ & $\mathrm{L}$ \\
\hline $\mathrm{NA}$ & $=$ & $\mathrm{L}$
\end{tabular}

Selanjutnya persamaan ini juga memenuhi unsur perubahan matematika baik $\mathrm{A}=\mathrm{L}+\mathrm{E}$ ataupun $\mathrm{A}-\mathrm{L}=\mathrm{E}$ menjadi Assets - Equity $=$ Liabilities $(\mathrm{A}-\mathrm{E}=\mathrm{L})$ adalah sangat memungkinkan. Entitas kepemilikan non profit, bisa mengedepankan kewajiban sebagai entitas utama dalam komponen pelaporan entitas berbanding kepemilikian.

Dapat di simpulkan bahwa persamaan sederhana dari entitas kewajiban sebagai aspek utama komponen perlaporan keuangan adalah Assets - Liabilities = Equity $(\mathrm{A}-\mathrm{L}=\mathrm{E})$.

\begin{tabular}{lll}
\hline $\mathrm{A}-\mathrm{E}$ & $=$ & $\mathrm{L}$ \\
\hline
\end{tabular}

\section{ENTITAS KEWAJIBAN YANG MENJADI PRIORITAS}

Warsono, (2009) menjelaskan lebih mendalam bahwa peran persamaan akuntansi untuk penggunaannya seharusnya tidak hanya berfungsi sebagai alat pendukung untuk menggambarkan realitas bisnis pada teknologi komputer akuntansi, namun juga berfungsi sebagai enabler dan transformator. Bagi penulis Transformasi disini ditujukan untuk penambahan permasalahan yang terjadi pada beberapa kasus dan tugas pembelajaran yang itu tidak sesederhana pemehaman teori. Sebagai perumpamaan untuk permasalahan kemungkinan perubahan tidak mempengaruhi pada sisi persamaan dasar akuntansi, missalkan seorang pembisnis memiliki beberapa asset baru dalam jumlah tertentu dengan menukar atau menggantikannya dengan nilai seimbang dengan asset lamanya.

Hal ini dipandang perlu untuk disajikan. Penulis berpendapat pada suatu waktu tertentu, perusahaan harus mengedepakan entitas kepemilikan non perusahaan, dalam arti luas adalah kewajiban, yang diprioritaskan untuk para calon kreditur, ataupun untuk para kreditur yang telah berinvestasi pada perusahaan. Terkadang mereka memberi kepercayaan kepada perusahaan melebihi dari entitas kepemilikan yang dimiliki oleh perusahaan itu sendiri. Dengan kata lain bahwa bisa jadi dalam upaya menyalurkan kredit, fasilitas yang diberikan adalah sepadan dengan keberadaan asset atau sebesar total asset. Jika hal ini terjadi maka perusahaan 


\section{PENERAPAN DOUBLE ENTRY BOOKKEEPING BASIS FOKUS PENERAPAN PADA LIABILITIES SEBAGAI KOMITMEN MORAL, TANGGUNG JAWAB DAN KINERJA LEMBAGA SOCIAL, PUBLIK DAN INSTITUSI PEMERINTAHAN}

harus lebih mengutamakan entitas pelaporan kewajiban berbanding kepemilikan.

Pengembangan yang ingin di ajukan dalam konsep ini bahwa $(A=L+E)$ sama $(A-L=E)$ berarti bisa juga $(A-E=L)$. Pendekatan pada rumus dasar Pacioli $(A=L+E)$, konsep yang sama dikembangkan oleh Weygendt et al., (2010) atau Needles \& Powers (2007). Persamaan untuk pengembangan konsep ini menurut penulis bahwa persamaan tersebut dibuat untuk penjelasan dan pengembangan persamaan akuntansi sebagai sebuah entitas kesatuan bisnis/usaha (Swardjono 2006).

Sementara Pada pendekatan Weetmen (2011) dan Alexander \& Nobes (2010) ada benarnya jika persamaan tersebut bisa di kembangkan menjadi ( $\mathrm{A}-\mathrm{L}=\mathrm{E}$ atau $\mathrm{E}=\mathrm{A}-\mathrm{L}$ ). Mereka memperkenalkan rumus akuntansi yang membuat persamaan berbeda dari Weygendt dan yang lainnya. Konsep yang di kembangkan ini merupakan suatu entitas bisnis untuk mengukur nilai kepemilikan murni maka harus mengedepankan kewajiban berbanding kepemilikan atau ekuitas. ketika suatu entitas bisnis untuk mengukur nilai kepemilikan murni maka harus mengedepankan kewajiban berbanding ekuitas (Swardjono 2006). Dalam arti lain penulis berpendapat bahwa entitas bisnis kepemilikannya adalah murni mayoritas unsur kewajiban.

Namun ini bertentangan dengan entitas kesatuan bisnis, pada kasus tertentu bisa saja sebuah asset dimiliki dengan cara kombinasi, seperti membeli mesin dengan cara utang dan modal sendiri. Namun ketika entitas kepemilikan ingin di lepas dari utang, mesin tidak bisa di pecah sesederhana rumus Weetmen, melainkan harus di pisahkan dengan mengganti atau menjualnya, atau entitas yang ingin mengukur kewajiban. Juga bisa dengan persamaan ( $A-E=L$ atau $L=A-E)$,

Asumsi yang muncul untuk pengungkapan aset bersih sama dengan kewajiban sebagai entitas utama dan tujuan utama unsur dan komponen pelaporan dari dasar persamaan sederhana tersebut $(A-E=L)$ artinya akan ada pengungkapan kelebihan atas entitas yang kepemilikannya tidak memiliki identitas (utang tanpa pemilik) untuk perusahaan tertentu yang berbasis non profit oriented.

Suwardjono (2006), mengungkapkan bahwa kewajiban memiliki karakteristik unsur pengorbanan manfaat ekonomi masa depan, keharusan saat ini untuk mentransfer asset, dan timbul akibat transaksi masa lalu.

Pengorbanan manfaat ekonomis masa depan menghendaki bahwa ada unsur yang dihilangkan dimasa depan untuk di ambil manfaatnya saat ini. Keharusan sekarang untuk mentransfer asset meyakinkan bahwa itu merupakan buah hasil dari kebijakan, ketentuan, ketetapan maupun keputusan yang ditetapkan saat ini sehingga berdampak pada perbaikan dan pemenuhan kebutuhan. Dan timbulnya akibat transaksi masa lalu dimaksudkan individu setelahnya meneriman manfaat ataupun komitmen akibat/kerugian karena keputusan masa lalu. Timbulnya manfaat bisa saja sebanding dengan beban yang muncul atau malah lebih besar beban yang dikorbankan dimasa depan dari manfaat yang dihasilkan.

Utang, orientasi pelaporannya bukan untuk kepemilikan, tetapi adalah 


\section{Husni Mubarak $^{1}$}

komitmen untuk pelaporan ke publik bahwa ada kebijakan dan keputusan pengelolaan yang di pertanggunjawab oleh manajemen selama komitmen pengelolaan yang imbas tindakan akan berefek pada pewarisan tanggungjawab secara moral dan pelaporan kepada penerus dikemudian harinya.

Bahwa kewajiban moral berupa hasil kebijakan yang akan di regenerasikan kepada pimpinan dan pihak penerus beruba beban utang dan kewajiban bunga atas utang untuk generasi penerus. Terlepas dari semua komitmen, kewajiban menjadi prioritas dengan alasan dan pertimbangan bahwa entitas usaha sosial, publik dan pemerintahan merupakan konsep kepemilikan publik yang pertanggung jawabannya hanya menginginkan konsep kebenaran, kesejahteraan dan kontribusi yang lebih luas lagi melebihi service dan good, bisa berupa trust dan sastifaction.

\section{PENGEMBANGAN MODEL PELAPORAN AKUNTANSI.}

Ketidak rasionalan pengungkapan entitas persamaan akuntansi terjadi ketika entitas tidak memenuhi kaidah dan rasionalitas unsur pelaporan keuangan. Laporan keuangan merupakan suatu kesatuan entitas pelaporan, tidak bisa dipisahkan antar satu dengan yang lainnya, meski perwujudannya adalah pengelompokan yang terpisah. Asumsi dasar ketika laporan akuntansi mengedepankan konsep kesatuan usaha untuk profit, dan kepemilikan (equity), kedua laporan ini adalah entitas yang muncul setelah kewajiban dijelaskan selama ini. Tidak mungkin bahwa suatu entitas untuk profit dan equitas bisa diketahui lebih dahulu dengan mengabaikan entitas kewajiban.

Tiapa entitas pelaporan bisa mengembangkan model dan konsep pelaporan keuangan dengan model basis akuntansinya masing-masing. Modifikasi persamaan akuntansi dari hukum positif $A=E+L$ berubah menjadi hukum negative ( $A-L=M$ atau $A$ $\mathrm{M}=\mathrm{L}$ ) ini menandakan bahwa itu merupakan komitmen matematik atas tujuan dan indikasi pencapaian akhir dari progress yang di harapkanl. Secara matematis hal ini benar dan tidak ada kesalahan, namun dimensi pemikiran lah yang menafsir dengan multi disiplin dan pemahaman untuk memaknai bahwa informasi yang dihasilkan adalah berbeda dan tidak sama.

Dengan pemahaman sederhana dapat di simpulkan bahwa $A=E+L$ merupakan entitas kesatuan Usaha, $A-L=E$ untuk mengukur entitas kepemilikan bersih/equity dari kepemilikan, dan $\mathrm{A}-\mathrm{E}=\mathrm{L}$ merupakan komitmen pertanggungjawaban dan kewajiban dari komitmen operasional dan usaha

Secara sederhana jika dikelompokkan, model satu adalah untuk laporan publik, model dua adalah untuk pemegang saham, dan model ke tiga adalah untuk pengelola usaha. Namun akan bermakna luas dan semu jika penerapan lebih di focus kepada kompetensi dan dimensi pembagian klaster kepemilikan dan satuan usaha dalam fungsi yang lebih signifikan.

Kecendrungan saat ini mengembangkan system keuangannya dengan biaya besar dan mahal, investasinya cukup besar. Karena karakteristik dari system keuangan yang rumit, sulit dan lama. Sehingga tidak jarang pengguna tertentu 


\section{PENERAPAN DOUBLE ENTRY BOOKKEEPING BASIS FOKUS PENERAPAN PADA LIABILITIES SEBAGAI KOMITMEN MORAL, TANGGUNG JAWAB DAN KINERJA LEMBAGA SOCIAL, PUBLIK DAN INSTITUSI PEMERINTAHAN}

menghabiskan dana yang banyak hanya untuk mengembangkan sistem nya. Secara simple terkadang mereka membelinya saja.

Sebenarnya kerumitan itu berawal dari konsep dan kerangka berfikir sistem yang rumit, sehingga terjadilah demikian. Jika system mampu di sederhanakan, sudah tentu pasti permasalahan bisa di selesaikan. Andai semua sektor lini keuangan memahami teknologi dan memahami sistem keuangan sebagai sebuah sinergisitas, sudah tentu pasti bisa di maknai sebagai sebuah yang lebih sederhana.

\section{KESIMPULAN DAN REKOMENDASI}

Untuk itu persamaan akuntansi $A=L+E$ bisa di modifikasi menjadi $A-L=E$ atau $A-E=L$ untuk kompleksitas transaksi. Dengan kata lain, dasar pemikiran Persamaan adalah bahwa sumber daya (Asset) harus selalu sama dengan sumber dana (Equity and Liabilities). Persamaan ini diperluas untuk mencakup unsur yang mewakili aktivitas ekonomi perusahaan yang lebih kompleksitas. Basis pelaporan apakah focus kepada konsep kesatuan usaha $(A=L+E)$, atau mengukur entitas kepemilikan bersih $(A-L=E)$ maupun sebagai komitmen pertanggungjawaban $(A-E=L)$ dari tiap-tiap elemen konsep laporan.

Tindakan yang rasional dari penulisan artikel ini adalah menjadikan sistem persamaan akuntansi lebih menfokuskan liabilities (kewajiban/utang) untuk lembaga sosial, publik, dan pemerintahan yang mana masyarakat sebagai pemilik utama. Public trust akan menikmati hasil komitmen kebijakan dan keputusan saat ini yang memberi perubahan dan dampak sebagai bagian komitmen moral dan tanggungjawab dari tugas individu yang di beri amanah tersebut. Serta perubahan ini di dedikasi untuk kebijakan dan manajemen pelaporan keuangan dimasa depan.

\section{UCAPAN TERIMAKASIH}

Ucapan terimakasih ditujukan kepada Jurusan Administrasi Niaga Program Studi Akuntansi Sektor Publik Politeknik Negeri Bengkalis tempat peneliti meniti karir dan juga Tim Jurnal Utility STKIP Nurul Huda.

\section{DAFTAR PUSTAKA}

Alexander, D and Nobes, C, Financial Accountingan International Introduction e4, Pearson Education Limited, England, 2010.

Albrecht, W. Steve, Stice, Earl K., and Stice, James D. 2008, Financial Accounting, 10 edition, Thomson Higher Education, USA

Anne Britton and Chris Waterston, 2006, Financial Accounting, 4 edition, Pearson Education Limited, England

Barry Elliott and Jamie Elliott, 2009, Financial Accounting and Reporting, 13edition, Pearson Education Limited, England

Belverd E. Needles, Marian Powers, 2007, Financial Accounting e9, Hougton Mifflin Company, Boston 
Belverd E. Needles, Marian Powers, Susan V. Crosson, 2008, Principle of accounting e10, Houghton Mifflin Company, boston, newyork,

Carl S. Warren, James M. Reeve, Jonathan E. Duchac, 2012, Financial Accounting $12 e$, Cengage Learning Mason USA

Ellerman, D, 1985, double entry multidimensional Accounting, omega, int $j$. of management scient vol. 14. No. 1 pp 13-22

2007, Double-Entry Accounting: The Mathematical Formulation and Generalization SSRN's eLibrary ld No. 1340619

2014, On double-entry bookkeeping: The mathematical treatment, Accounting Education: An International Journal, 23(5), 483-501.

Horngren, C.T, \& Harrison, W.T. Jr, 2012, Accounting Secon Edition, Prentice-Hall Inc, Englewood Cliffs, New Jersey

Harry and Weetman, P, 2011, Financial Accounting An Introduction Fifth Edition, Pearson Education Limited, England

Mubarak, Husni, 2017, "Unrationality Study Double Entry Bookkeeping" Solusi Pengembangan Persamaan Akuntansi pada Presfektif Pembelajaran, Kasus dan Pemahaman yang Universal, Vol 5, No 2, Inovbiz Polbeng

(2017) Double Entry Book keeping transformasi penyederhanaan konsep \& pemahaman pada perbedaan presfektif pembelajaran akuntansi, SNIT Polbeng. (2018) "Complicated mathematic DEB accounting consept" Penggunaan dan penerapan untuk kerangka pembelajaran pada Accounting Scients and Accounting Problems. Vol 6, No 2, Inovbiz Polbeng

Ian Gillespie, Richard lewis, kay hamilton. Principles of financial accounting E3. Pearson Education Limited, England, 2004

Jerry J. Weygandt, Paul D. Kimmel, Donald E. Kieso. Accounting principle e10. John Wiley \& Sons, Inc. US 2012

Nobes, C, 2015, The International Transfer of Technology: Examples from the Development of Accounting European Accounting and Management Review, vol 2 Issue 1

Robert Libby, Patricia Libby, Daniel Short, 2009, Financial accounting e6, McGrawHill NewYork

Suwardjono, 2006, Teori Akuntansi Perekayasaan Pelaporan Keuangan, Edisi 3, BPFE Yogyakarta

Stickney,P.C, Weil,R.L, Schipper,K, and Francis, J, 2010, Financial Accounting An Introduction To Concepts, Methods and Uses, 13edition, south-western cengage learning, USA

W. Steve Albrecht, Earl K. Stice, and James D. 2008, Stice Financial Accounting, e10, Thomson Higher Education, Mason, OHaio USA

Weetman, Pauline, 2011, Financial Accounting An Introduction, 5 edition, Pearson Education Limited

Warsono, S, 2009, Using mathematics to answer correctly the mechanism of debit and credit, SSRN's eLibrary ld No. 1439057 ,2009, Mathematics in accounting as a big unanswered Question, SSRN's eLibrary ld No. 1439084

Weygant, 2012, Accounting Principles, e5, John Wiley \& Sons, Inc. England.

Weygandt, J.J, Kimmel, P.D, and Kieso, D.E, 2010, Financial Accounting, 7th

Edition, John Wiley \& Sons, Inc. England 